\title{
Does Post-Activation Potentiation Protocols affect Anaerobic Performance in women Taolu Wushu Athletes?
}

\author{
José Afonso
}

University of Porto

Hengameh Moradian

Razi university

Rasoul Eslami

Allameh Tabatabaei University

Alexandre Martins

University of Poro

Abdolhossein Parnow ( $\sim$ parnowabdolhossein@gmail.com )

Razi university

\section{Research Article}

Keywords: Warm-up, RAST test, Anaerobic power, Fatigue

Posted Date: October 1st, 2021

DOI: https://doi.org/10.21203/rs.3.rs-952463/v1

License: (9) This work is licensed under a Creative Commons Attribution 4.0 International License. Read Full License 


\section{Abstract}

Introduction: Post-activation potentiation has an influence on short duration and high intensity function. This study aimed to answer this question whether post-activation potentiation protocol in different models has effect on anaerobic performance in women Wushu athletes.

Methods: Women elite Taolu Wushu athletes participated in current crossover design study. (i) specific Wushu WU (Wushu WU); (ii) Strength-based WU (StreWU); and (iii) Speed-based WU (SpeWU) were performed by Wushu athletes in three inconsecutive days separated by $48 \mathrm{~h}$. Five minutes after each WU protocols, Running-Based Anaerobic Sprint Test (RAST) was performed. Heart rate, immediately, and blood lactate were measured for 4 times: before WU protocols, immediately after WU protocols, before RAST, immediately after RAST.

Results: Data analysis revealed significant differences in 4 time points of lactate levels $(p=0.001 ; d=1.71)$, although no significant difference among protocols was observed. Values of variables obtained from RAST showed that StreWU had a significant impact on minimum power $(p<0.05 ; d=-0.795)$ comparing to WushuWU and on fatigue index comparing to SpeWU ( $p<0.05 ; d=-0.799)$. No significant differences were found among the WU protocols for peak power and mean power.

Conclusion: All WU protocols had mostly the same effect, and PAP was not very effective. Possibly, the WU protocols generated too much fatigue, due to the short-term rest time. However, longer intervals would likely enter the realm of post-activation performance enhancement, which is distinct from PAP.

\section{Introduction}

Wushu is the general name of all Chinese martial arts which nowadays, considers as an international Olympic game [1]. Wushu performs in two different styles: Taolu (forms-based) and Sanda (fighting)[1]. Taolu style is characterized by martial forms which includes applied skills in fighting such as punching, kicking, defensive and offensive techniques, centralization, balanced movements, jumping, launching techniques, as well as using different kinds of weapons [2]. The form performance duration is about 80 seconds which can be supplied mainly from the glycolytic system along with performing by speed, strength or a combination of both [2]. According to a research done on the Brazilian Olympic Taolu Wushu team, the blood lactate level can reached to $10.2 \pm 1.5 \mathrm{mmol} / \mathrm{L}$ (in average) in women Taolu Wushu athletes after performing Taolu forms, which support the idea of a major contribution of the glycolytic system, [1]. Coaches and athletes are consistently searching for training methods that provide optimization for the performance [3]. Among others, a proper warm-up (WU) may positively affect the performance in training and competitive scenarios [4].

In martial arts, speed, strength and power are key-elements of performance and their optimization in training or competition can be enhanced through an appropriate WU [5]. The expected effects of this phase of the training session (WU) are to achieve optimum performance by preparing the athletes 
system for more strenuous activities [6]. There are many different WU strategies, therefore, it is important to research the differential effects of distinct protocols. For example, one of the traditional elements included on WU is the static or dynamic stretch [7], despite the fact that some studies have suggested that static stretching resulted in a temporary decrease of strength, power, and speed of the subsequent action $[8,9]$. Proposed mechanisms for the decrement in skeletal muscle force generation are that static stretching temporarily reduces musculotendinous unit stiffness and neural drive. Ultimately, this may place an athlete at a short-term disadvantage in activities that require skeletal muscle to develop large amounts of force rapidly [10]. However, according to the standardized questionnaire at the Olympic training center, $80 \%$ of the athletes performed regular static stretches before both practice and competition [7]. The decrease of strength, power, and speed can cause a drop in performance, especially in Taolu athletes, who need these factors for performing Taolu style. The reason could be due to the lack of knowledge of some coaches and athletes about the negative influences of static stretches or mental issues [7], as well as the gap between scientific knowledge and practice.

In order to minimize the negative influences of more traditional approaches to $\mathrm{WU}$, post activation potentiation (PAP) has been taken into consideration. PAP has been defined as a neuromuscular facilitative phenomenon after acute neuromuscular excitation [11]. Previously, the effects of PAP have been studied, considering different training levels (e.g., untrained, trained, and competitive athletes) and the effects of each training level on muscle physiology and architecture that may influence the PAP response [11]. The mechanisms of PAP are still not consensually defined (different theories are still in discussion, namely including phosphorylation of the regulatory light chains, potentiated $\mathrm{H}$-reflex response or pennation angle of the muscle fibers), but it seems that, in practice, the PAP may provide acute improvements on the subsequent performance [12]. Also, it has been brought to attention that periods longer than 3-5 minutes may actually be explained by different physiological phenomena, and there has been a debate suggesting that PAP should be differentiated from post-activation performance enhance or PAPE $[13,14]$.

Moreover, It seems that the relationship between neuromuscular excitation and rest time plays an important role in the beneficial effect of PAP on the performance, due to the much-needed balance between PAP and fatigue [15]. It has been indicated short WU followed by an intense/ or more prolonged PAP workout, would eventually have resulted in greater potentiation effect [16]. In contrast to this regard, a study used a prolonged WU in adolescence swimmers. They performed four trial conditions (three experimental, one control) on different days. The control trial involved a standardized 1200-m warmup followed by $30 \mathrm{~min}$ of rest and a maximal $50-\mathrm{m}$ freestyle swimming sprint. The experimental trials involved the same protocol but added a PAP component after a 20 -min rest (10 min pre-50-m). The different PAP component involved the subjects in completing a 30-s maximal effort of: (1) push-ups (PU - upper body), (2) squats (SQ - lower body), and (3) burpees (BP - lower and upper body) The authors demonstrated no impact of 30-s PAP exercises on the 50-m freestyle sprint performance in the 10 min prior to the event in young swimmers [17]. Although their results could probably be due to the long recovery period post-PAP, it seems the mechanisms involving fatigue would likely surpass any benefits 
from long warm-ups and PAP protocols. Also, it is possible that an interplay exists between mechanisms associated with PAP and PAPE $[13,14]$.

Potentiation can be induced in different ways (e.g., maximum voluntary contraction (MVC), heavier submaximal load, plyometrics), although the most common method is the use of MVC [18]. A metaanalysis performed by Wilson et al [19] suggested that intensities of 60-84\% 1 repetition maximum (RM) were optimal for inducting PAP, in which more sets were used for more experienced people and less sets for people with less experience [20]. Hypothetically, an increase in neural activity resulting from a maximum or a near maximum contraction may recall ability and synchronizing movement units for the next exercise actions and also reducing the inhibition of the Golgi tendon organ (GTO) helping by neural cooperation with PAP [21]. PAP can have a compensative role at excitation-contraction coupling (ECC) disorder which occurred during fatigue and by increasing the rate of force development (RFD) with an increased function at jumping, hitting and launching [11]. Training with heavy load could result in fatigue and covers PAP influences. Increased muscular power as a result of PAP disappeared after $30 \mathrm{~min}$ and overcoming fatigue happens one minute after stimulation, so most studies used 5-10 min of rest after warming up by PAP [22].

Some studies showed the influences of PAP on the function of speed and power of athletes [23,24]. To the best of our knowledge, however, the influences of PAP in sports like Wushu in which the glycolytic system is the main supplier of energy have not been investigated. With considering to Wushu as a top world-class sport and excellent IWUF ranking for Iranian women [25], studies in current papulation and PAP approach in Wushu athletes are limited. Therefore, this investigation can have a considerable role in Wushu's growth and in better understanding how different types of WU affects PAP. The aim of this study, therefore, was to determine the acute effects of different WU protocols (specific Wushu WU vs. strengthbased WU vs. speed-based WU) on anaerobic performance during a repeated sprint test and blood lactate in female Taolu Wushu athletes.

\section{Methods}

\section{Experimental approach to the problem}

This study followed a crossover research design. Ten elite Taolu Wushu female athlete's volunteers participated in the study. All subjects completed the 3 different WU protocols on non-consecutive days (48h): (i) Wushu WU protocol [WushuWU]; (ii) strength-based WU protocol [StreWU]; (iii) speed-based WU protocol [SpeWU]. The conditions were simply randomized. Seventy-two hours before the intervention, the Taolu wushu athletes were tested in body composition components (height, weight, body fat percentage), body mass index (BMI), and back squat strength and speed at 35-m running to calculated different percentage of 1RM and Max Speed using in ii and iii protocols, when they have not executed any high intensity exercise and have been in well-rested situation. Body mass and stature, 1RM tests were performed in a room with a stable temperature of $22 \pm 2^{\circ} \mathrm{C}$ and relative humidity of $48 \pm 3 \%$. The speed test 
protocol consists in 5 minutes of jogging, 5 minutes of static and dynamic stretching and 5 minutes of jumping movements.

\section{Subjects}

Ten elite Taolu Wushu women athletes (age: $19.9 \pm 3.3$ years old; height: $160.0 \pm 3.7 \mathrm{~cm}$; body mass: $54.7 \pm 5.2 \mathrm{~kg}$; body mass index: $13.3 \pm 3.4 \%, 21.2 \pm 1.5 \mathrm{~kg} / \mathrm{m}^{2}$ ) were recruited to participate in this study. The inclusion criteria were: (i) having experience in the Iran athletic championship; (ii) having resistance training experience (including squat) at least during last one year; (iii) not having had injuries or illnesses in the two months prior to the study. Mean baseline values and standard deviation of estimated $1 \mathrm{RM}$ at back squat and speed at 35 meters running (tested 72-h before the beginning of the experimental protocol) were $53.9 \pm 27.2 \mathrm{~kg}$ and $6.43 \pm 1.21 \mathrm{~s}$, respectively. Information about the study design and experimental approach was provided to participants, as well as the benefits and risks. After their agreement, participants signed an informed written consent. The study was approved by the Ethics Committee of the Razi University, Kermanshah, Iran. The study followed the ethical standards of Declarations of Helsinki (2013 updated version) for human studies.

\section{Procedures}

Body composition and Laboratory Measurements. Height $(\mathrm{cm})$ was measured using a stadiometer (Seca, 213 , Germany) (ICC=0.99) with the participant's head in the Frankfort plane [26] in which the athletes were assessed without shoes and in standing position. Body mass $(\mathrm{kg})$ and composition data were estimated using a multi-frequency bioelectrical impedance analyzer (Zeus 9.9 PLUS; Jawon Medical Co. Ltd. KungsangBukdo, South Korea). BMI was calculated by dividing body mass by the square of height. For blood lactate level concentration, fingertip blood lactate (Lactate Scout+, Cosmos Sirius, Germany) were taken at baseline before and after WU, before and after RAST.

Back Squat Strength and Speed Assessment. Back squat 1-RM (performed at a Smith machine) was estimated by Brzycki 1-RM prediction equation (Brzycki, 1993): $\frac{\text { Liftedload }(\mathrm{kg})}{(1.0278-0.0278 \times \text { repeationnumber })}$ (ICC=0.99). Speed was assessed via 35-m sprint running for 2 times (reported in average) separated by 5minute rest to full regeneration. The time for each sprint was assessed using a photocell (Optical lap-time watcher Hamamatsu photonics K.K, ICC=95) [27].

Warm up protocols. In WushuWU protocol, based on previous publications [1, 2] it was established as the Taolu wushu athletes generally perform WU before competition. Briefly, it consisted in 5 minutes of slow running (approximately $60 \%$ of HRmax), stretching (The performed stretches were chosen to mimic some of the common stretches performed by athletes and were held for 15 seconds per side) and jumping ( $2 \times 10$ repetition hip adduction, $2 \times 10$ repetition hip abduction, $2 \times 10$ repetition butt kicks, $2 \times 10$ repetition knee raises and $2 \times 10$ repetition straight leg march). After a 5-minute general activity with low intensity and stretching, the StreWU protocol that consisted at two sets of four repetitions (made at maximal intent), executed at $70 \%$ of the estimated 1RM, was executed. Rest time was one minute between sets. Thn nratannl far ctralall I $n n n$ hn faund in n nrevious work [28]. The SpeWU consisted of running 40 yards 
with $0,10,20$ and 30 body resistance percentage (speed protocol) and executed after a 5-minute general low intensity activity and stretching. In the SpeWU protocol, the relative weight was attached to a rope tied to athlete's west. Rest time was one minute between exercises. The detail information about the SpeWU protocol can be found in a previous study [29]. Total time for WU in all protocols was 15 minutes so that the first 5 minutes (including slow running and stretching) was similar for all protocols. The athletes were distributed in three groups and in the first day the members of each group performed one of the protocols and on this order each group protocol was changed. For every athlete, a 5-minute rest was provided between WU and repeated sprint test (RAST). This interval was used specifically to assess PAP and avoiding entering more deeply into PAPE-related effects.

Repeated sprints test. Five-minutes after executing the WU protocols, the running-based anaerobic sprint test (RAST) was performed. Before and after the WU protocols (immediately), before and after the RAST (immediately), blood lactate concentration was assessed using a fingertip blood lactate (Lactate Scout+, Cosmos Sirius, Germany) (ICC $=0.93 \& 0.95)$ [30]. and rest heart rate $(\mathrm{RHH})$ and maximum HR (MHR) was measured (Polar Electro Inc., Lake Success, Finland) (ICC >0.99) [31] to follow HR changes from rest to maximal work and to make sure of maximum effort of subjects. The RAST consisted in six-sprints over a 35-m distance separated by a 10-second recovery between each sprint. The time for each sprint was assessed using a photocell (Optical lap-time watcher Hamamatsu photonics, K.K) (ICC=95) [27]. The RAST seems to be a suitable way for assessing anaerobic power where the lactate amount at the end of test is near its rate after performing Taolu wushu form [1]. Based on duration of each sprint running and the athlete's body mass, maximum power at a trial and minimum power at a trial, the average power and fatigue index were calculated using the formulas of [(body mass $\times$ distance $\left.^{2}\right) /$ time $\left.^{3}\right]$ and $[($ minimum power-maximum power) / total running time], respectively.

\section{Statistical analysis}

Results are presented in form of tables and figures presenting mean and standard deviation. Data was preliminary tested for normality and homogeneity using the Shapiro-Wilk test and the Levene test, respectively. After observation of the assumptions of normality ( $p>0.05)$ and homogeneity $(p>0.05)$, a repeated measures ANOVA tested the variations of blood lactate, HR and RAST measures between WU protocols. Pairwise comparisons were tested using the paired samples T test. The standardized effect size of Cohen (d) was used to determine the magnitude of changes in pairwise comparisons. The magnitude of changes was defined using the following thresholds: with 0.2 considered as a small ES, 0.5 as a moderate ES and $>0.8$ as a large ES [32]. Descriptive statistics and inference tests were executed in the SPSS software (version 21.0, IBM, USA) for a $p \leq 0.05$.

\section{Results}

Demographic data including height, body mass, and other, as well as pre-test values for Back Squat 1$1 \mathrm{RM}$ and 35-m sprint run are presented in Table 1. Although anthropometric data and the sprint run have 
a relatively low dispersion surrounding the mean, there was considerable inter-individual variation with regard to the back squat 1-RM test.

Table 1

Demographic data for subjects

\begin{tabular}{|lll|}
\hline Variables & Mean & Standard deviation \\
\hline Age (years) & 19.90 & 3.31 \\
\hline Height (m) & 1.60 & 0.03 \\
\hline Weight (kg) & 54.68 & 5.18 \\
\hline Body fat (\%) & 13.35 & 3.37 \\
\hline BMl (kg/m $\left.{ }^{2}\right)$ & 21.19 & 1.46 \\
\hline Back Squat 1-RM & 53.90 & 27.20 \\
\hline 35-m sprint Run & 6.43 & 1.21 \\
\hline
\end{tabular}

Performance at RAST and lactate concentrations can be found in Tables 2 and 3, respectively. In Table 2, only two out of twelve comparisons showed statistically significant differences, meaning that overall the three different warm-up protocols generated similar results. StreWU had a significant impact on minimum power $(p=0.002 ; d=-0.795)$ comparing to WushuWU and on fatigue index comparing to SpeWU $(p=0.024$; $d=-0.799)$. No significant differences were found among the WU protocols for peak power and mean power. Furthermore, most values presented small standard deviations, meaning that the responses were consistent and did not present great inter-individual variability. 
Table 2

Components of anaerobic performance in RAST test

\begin{tabular}{|c|c|c|c|c|c|c|}
\hline Measures & WushuWU & StreWU & SpeWU & $\begin{array}{l}\text { Pairwise } \\
\text { comparisons }\end{array}$ & $\mathrm{p}$ & d \\
\hline \multirow{4}{*}{$\begin{array}{l}\text { Max power } \\
(\mathrm{w} / \mathrm{kg} / \mathrm{m})\end{array}$} & \multirow[t]{4}{*}{$5.01 \pm 1.48$} & \multirow[t]{4}{*}{$5.13 \pm 0.99$} & \multirow[t]{4}{*}{$5.51 \pm 1.56$} & \multirow{2}{*}{$\begin{array}{l}\text { WushuWU vs. } \\
\text { StreWU }\end{array}$} & 0.184 & -0.14 \\
\hline & & & & & 0.206 & -0.35 \\
\hline & & & & $\begin{array}{l}\text { WushuWU vs. } \\
\text { SpeWU }\end{array}$ & 0.101 & -0.28 \\
\hline & & & & StreWU vs. SpeWU & & \\
\hline \multirow{4}{*}{$\begin{array}{l}\text { Mean power } \\
(\mathrm{w} / \mathrm{kg} / \mathrm{m})\end{array}$} & \multirow[t]{4}{*}{$3.83 \pm 0.78$} & \multirow[t]{4}{*}{$4.19 \pm 0.86$} & \multirow[t]{4}{*}{$4.1 \pm 1.06$} & \multirow{2}{*}{$\begin{array}{l}\text { WushuWU vs. } \\
\text { StreWU }\end{array}$} & 0.120 & -0.41 \\
\hline & & & & & 0.143 & -0.20 \\
\hline & & & & SpeWU & 0.135 & 0.07 \\
\hline & & & & StreWU vs. SpeWU & & \\
\hline \multirow{4}{*}{$\begin{array}{l}\text { Min power } \\
(\mathrm{w} / \mathrm{kg} / \mathrm{m})\end{array}$} & \multirow[t]{4}{*}{$2.9 \pm 0.34$} & \multirow[t]{4}{*}{$3.42 \pm 0.53$} & \multirow[t]{4}{*}{$3.13 \pm 0.55$} & \multirow{2}{*}{$\begin{array}{l}\text { WushuWU vs. } \\
\text { StreWU }\end{array}$} & $0.002^{*}$ & -0.79 \\
\hline & & & & & 0.283 & -0.34 \\
\hline & & & & SpeWU & 0.102 & 0.35 \\
\hline & & & & StreWU vs. SpeWU & & \\
\hline \multirow[t]{4}{*}{ Fatigue index (w/s) } & \multirow[t]{4}{*}{$2.79 \pm 1.55$} & \multirow[t]{4}{*}{$2.33 \pm 0.72$} & \multirow[t]{4}{*}{$3.23 \pm 1.42$} & $\begin{array}{l}\text { WushuWU vs. } \\
\text { StreWlI }\end{array}$ & 0.278 & 0.38 \\
\hline & & & & & 0.164 & -0.29 \\
\hline & & & & $\begin{array}{l}\text { WushuWU vs. } \\
\text { SpeWU }\end{array}$ & $0.024 *$ & -0.79 \\
\hline & & & & StreWU vs. SpeWU & & \\
\hline
\end{tabular}

Table 3 suggests a similar response, with only one statistically significant difference in twelve comparisons. Data analysis showed, in all protocols, there are significant differences between BWU and AWU ( $\mathrm{p} \leq 0.001, \mathrm{~d}=-1.79, \mathrm{p} \leq 0.001, \mathrm{~d}=-3.03, \mathrm{p} \leq 0.001, \mathrm{~d}=-3.24$, in WushuWu, StreWU, and SpeWU, respectively), BWU and after RAST ( $p \leq 0.001, d=-4.08, p \leq 0.001, d=-3.99, p \leq 0.001, d=-5.59$ in WushuWu, StreWU, and SpeWU, respectively), AWU and after RAST ( $p=0.002, d=-1.27, p=0.030, d=-0.8, p=0.004, d=$ -1.38 , in WushuWu, StreWU, and SpeWU, respectively), before RAST and after RAST ( $p \leq 0.001, d=2.41$, $p \leq 0.001, d=-2.28, p \leq 0,001, d=-1.73$, in WushuWu, StreWU, and SpeWU, respectively). In addition, there was a significant difference between AWU and before RAST in WushuWu and StreWU protocols $(p=0.040$, $d=0.81, p=0.003, d=1.36$, respectively), as well as our finding show a significant difference between BWU and before RAST in StreWU, and SpeWU protocols ( $p=0.004, d=-1.95, p \leq 0.001, d=-1.96$, respectively). In SpeWU, between AWU and after RAST, also, was shown a significant difference $(p=0.004, d=-1.38)$. There were no significant differences between other times $(p \leq 0.05)$. 
Overall, the three warm-ups produce similar effects and all generated statistically significant differences with respect to before the warm-up. In line with this data, further analysis showed that after hypothesizing Mauchly's test of Sphericity, there was no significant difference between the three warm up methods for maximum anaerobic power variable $(p=0.184)$. Also, there was no a significant difference between the three warm up methods for anaerobic power average variable $(p=0.125)$ (Figure 1, Table 3).

Table 3

Lactate plasma levels $(\mathrm{mmol} / \mathrm{l})$ for the three protocols

\begin{tabular}{|c|c|c|c|c|c|c|}
\hline $\begin{array}{l}\text { Period of } \\
\text { assessment }\end{array}$ & WushuWU & StreWU & SpeWU & $\begin{array}{l}\text { Pairwise } \\
\text { comparisons }\end{array}$ & p & $\begin{array}{l}\text { d l } \\
\text { Magnitude }\end{array}$ \\
\hline \multirow[t]{4}{*}{$\begin{array}{l}\text { Before warm up } \\
\text { (BWU) }\end{array}$} & \multirow[t]{4}{*}{$4.2 \pm 1.7$} & \multirow[t]{4}{*}{$3.8 \pm 1.6$} & \multirow[t]{4}{*}{$3.6 \pm 1.3$} & \multirow{2}{*}{$\begin{array}{l}\text { WushuWU vs. } \\
\text { StreWU }\end{array}$} & 0.609 & 0.181 \\
\hline & & & & & 0.432 & 0.249 \\
\hline & & & & SpeWU & 0.078 & 012 \\
\hline & & & & $\begin{array}{l}\text { StreWU vs. } \\
\text { SpeWU }\end{array}$ & & \\
\hline \multirow{4}{*}{$\begin{array}{l}\text { After warm up } \\
\text { (AWU) }\end{array}$} & \multirow[t]{4}{*}{$10.8 \pm 4.8$} & \multirow[t]{4}{*}{$12.4 \pm 3.6$} & \multirow[t]{4}{*}{$11.9 \pm 3.4$} & $\begin{array}{l}\text { WushuWU vs. } \\
\text { StreWU }\end{array}$ & 0.372 & -0.382 \\
\hline & & & & Wuchulat I & 0.513 & -0.287 \\
\hline & & & & SpeWU & 0.808 & 0.125 \\
\hline & & & & $\begin{array}{l}\text { StreWU vs. } \\
\text { SpeWU }\end{array}$ & & \\
\hline \multirow{4}{*}{$\begin{array}{l}\text { Before RAST test } \\
\text { (BRAST) }\end{array}$} & \multirow[t]{4}{*}{$7.2 \pm 3.7$} & \multirow[t]{4}{*}{$8.1 \pm 2.6$} & \multirow[t]{4}{*}{$9.9 \pm 4.3$} & WushuWU vs. & 0.608 & -0.261 \\
\hline & & & & & 0.107 & -0.669 \\
\hline & & & & SpeWU & 0.261 & -0.521 \\
\hline & & & & $\begin{array}{l}\text { StreWU vs. } \\
\text { SpeWU }\end{array}$ & & \\
\hline \multirow{4}{*}{$\begin{array}{l}\text { After RAST test } \\
\text { (ARAST) }\end{array}$} & \multirow[t]{4}{*}{$16.3 \pm 3.8$} & \multirow[t]{4}{*}{$15.5 \pm 3.7$} & \multirow[t]{4}{*}{$16.3 \pm 2.9$} & $\begin{array}{l}\text { WushuWU vs. } \\
\text { StreWu }\end{array}$ & 0.591 & 0.226 \\
\hline & & & & & 1.00 & 0.000 \\
\hline & & & & $\begin{array}{l}\text { Wushuw } \\
\text { SpeWU }\end{array}$ & 0.591 & 0.254 \\
\hline & & & & $\begin{array}{l}\text { StreWU vs. } \\
\text { SpeWU }\end{array}$ & & \\
\hline
\end{tabular}

The statistical analysis revealed that the results of minimum power as a result of three protocols showed significant differences $(p=0.002)$ as can be observed in figure 1 . There was a significant difference between fatigue index in the strength and the speed protocols $(p=0.024) ;(d=0.799)$. The difference Loading [MathJax]/jax/output/CommonHTML/jax.js :ols in minimum power was higher (8\%) in the strength 
protocol and the difference between the strength and the speed protocol in fatigue index was higher $(27.9 \%)$ in the speed protocol.

\section{***Figure 1 near here***}

There was a significant difference between measurement times while investigating the effect of the three different protocols on lactate plasma levels at different times, before and after warm up and before and after the RAST ( $p=0.001$ ) (Figure 2). There was no significant difference specified between three warm up methods $(p \leq 0.05)$.

\section{***Figure 2 near here}

\section{Discussion}

The effects of warm-ups protocols aiming to promote post-activation potentiation in Wushu have not been properly analyzed. So, considering the scarce literature on the subject, the purpose of this study was to investigate the acute results of different warm-up protocols on anaerobic functions and lactate plasma levels in female Taolu athletes. Overall, the results of this research showed that there was a significant difference between the four lactate measurements, minimum power and fatigue index. In addition, there was no significant difference between maximum anaerobic power, average anaerobic power and lactate plasma levels with three warm up protocols. All protocols seem to be equally effective and could therefore be used interchangeably, at least in terms of the variables that were analyzed in this study. It is possible that neuromuscular responses could have been more specific to the type of warm-up used.

As our findings present all three WU protocols, WushuWU, StreWU, and SpeWU, showed a significant increase in blood lactate in comparison to before the warm-up, with a subsequent decrease after a 5minute rest and after performing RAST (again, too assess the effects of PAP and not PAPE). Specific warm-up is a common activity in Taolu, including a collection of traditional movements consisting of light aerobic activity, with static and dynamic stretching used before competitions [33]. The specific warm-up places an emphasis on getting the body ready for the physiological demands of the Taolu. In other words, the lactate concentration previously has been reported to be $10.2 \pm 1.5 \mathrm{mmol} / \mathrm{L}$ after performing Taolu form [1]. We therefore designed different warm up protocols based on some activities that performed to make a pressure on anaerobic energy system that is a main energy source involved in Taolu. We found that blood lactate was increased after warm up (10.8-12.4 mmol/L) and RAST (15.5$16.3 \mathrm{mmol} / \mathrm{L}$ ) almost at the same level of the blood lactate concentration during performing Taolu form [1] and that values reported by Goodwin et al. [34]. One of the standards of reaching $\mathrm{VO}_{2} \mathrm{max}$ is a lactate concentration of 8-12 mmol/L [35], meaning that RAST did promote maximal exertion. In a research done on cyclists, the validity of the RAST with the Wingate test was compared. The lactate concentrations in the RAST were $7.7 \pm 1.9$ and $8.0 \pm 1.9$ and $6.2 \pm 1.6 \mathrm{mmol} / \mathrm{L}$ at the rest times 4,8 and 12 minutes after the test, respectively [36]. Overall, the results of present study show that subjects performed RAST with highest attempts and we also can figure out that performing RAST test can be a suitable pattern for Loading [MathJax]/jax/output/CommonHTML/jax.js 
Wushu athletes at Taolu style. It also can be assumed that all three warm-up methods (special for Wushu athletes and PAP methods) had a similar impact on lactate concentration, and it is possible that the pressure on athletes is the same. In this regard, our data about blood lactate after RAST and the blood lactate values reported previously $[1,34]$ could be conformation why we used RAST to monitor variables involved in Taolu form. As we mentioned Taolu performance take place about 80 seconds with involving mainly glycolytic system with performing high intensity and short duration[2], RAST was a suitable activity pattern to put the same exertion and intensity on variables involved in Taolu form.

Among the factors considered to be efficient for warm up activities like PAP and its efficiency, training status and type of individual activity are other factors that can play an important role in warm up process. It is possible that participants have benefited from the intervention, while others have seen their performance impaired. It has been suggested that the most desirable response of PAP has been demonstrated in trained people and competitive athletes [19], although contradictory findings have been reported [37]. In our study, data is supporting the latter: The Wushu athletes under investigation had enough experience and all of them were the Iran and Kermanshah athletes, and Wushu itself is a sport requiring a combination of speed, power and force. This points to PAP being a very complex phenomenon, where a proper balance between potentiation and fatigue have to be achieved, and this balance might be highly individualized [38].

Our findings showed that the minimum power and fatigue index were significantly different. Some researchers reported same result as the present investigation [5,20,24], but the study of RAST and on athletes with physiological feature similar to Wushu athletes, was not found. Still, Till et al. investigated the PAP effect on sprint and jump performance of male academy soccer players and showed that these functions did not have any significant change [5]. Another study [24] examined the total change of jump and maximum jump, peak power, vertical peak force, rate of force development and relative force, and observed that there was no significant difference in variables, but the displacement rate in PAP group was more than non-PAP groups. Also, an investigation explored if changes in muscle architecture affected PAP [20], and the results showed that protocols did not create any significant difference in the performance of the vertical jump, but protocols with moderate and high intensity made some intensive changes in muscle architecture. Performing PAP programs, involved energy producer systems and athletes' experiences can be the main factors of existed differences. The significant difference was reported on the group that performed the strength protocol. For example, StreWU, including 2 sets and 4 repeats of Squat with $70 \% 1 \mathrm{RM}$, had a significant impact on minimum power comparing to WushuWU ( $3.42 \mathrm{vs} .2 .9 \mathrm{w} / \mathrm{kg} / \mathrm{m}$ ) that means StreWu probably prevent force output reduction during RAST protocol and maintain the difference between peak power and minimum power with lowest variation. This could provide athlete in situation to perform RAST with high stability and show lower fatigue index.

On the contrary, several studies reported the increase of power function or speed after PAP [39-43]. For example, Linder et al. [41] investigated the effects of preload 4 repetition maximum on 100m sprint times in collegiate women. The results showed that the PAP group had 0.19 seconds improvement in the $100 \mathrm{~m}$ 
swimming, by investigating the effect of PAP on the speed swimming performance. A significant improvement in $100-\mathrm{m}$ freestyle swim time ( 0.54 seconds) has been reported for the PAP trial vs. the control trial [21]. The PAP response was also investigated on recreational trained athletes and showed that PAP is a suitable and durable method for increasing the explosive force performance of athletes [44]. Other authors evaluated the acute effects of PAP in Special Judo Fitness Tests (SJFT), and showed that contrast exercise (maximum force combined with plyometric exercises) before SJFT lead to an increase in power and speed of Judo performers more than plyometric or maximum force interventions separated [23]. Furthermore, a study concluded that the use of 1 to 3 sets of half squats performed at moderate to high training loads ( $1 \mathrm{RM}, 3 \mathrm{RM}, 5 \mathrm{RM}$ and $60 \% 1 \mathrm{RM}$ ) may be a very effective strategy to meaningfully improve explosive performance of Counter Movement Jump (CMJ) in highly trained subjects [45]. Perhaps our study is suggesting that RAST may not be the most sensitive test to denote PAP, while vertical jumping tests may deliver better information. Another relevant issue concerns the balance between PAP and fatigue. It is also possible that our warm-up protocols have produced too much fatigue, impairing any benefits from PAP, because the mechanisms involving fatigue would likely surpass any benefits from PAP protocols. Alternatively, maybe such a prolonged warm-up (especially considering the nature of the competitive distance) brings such fatigue levels that the addition of PAP protocols in that timing are inducing more additional fatigue than an effective potentiation [16]. With a longer recovery time after PAP followed by a more prolonged and/or intense PAP workout, perhaps the desired potentiation effect would have been achieved. However, such potentiation could perhaps rely more on mechanisms behind PAPE, instead of the mechanisms involded in PAP.

Importantly, a difference in individual force (such as was observed in back squat 1RM) might influence the time of potentiation of subjects; after revocation stronger person needs less rest (5-10 min), while weaker person needs more durable rest (15-20 $\mathrm{min}$ ) [22]. Even when performing a given set of repetitions with a pre-stipulated range of repetitions, these might widely diverge for the same percentage of 1-RM [46]. The variety of responses in people showed that in order for developing the performances, PAP should be considered individually $[38,45]$ and with regard to factors like method, volume, load, recovery and other individual differences.

In summary, all three warm-up protocols showed similar effects on blood lactate concentration from rest to after warm-up, before and after the RAST. Also, with the exception of the minimum power and $\mathrm{Fl}$, other factors like peak power and mean power showed the same results in all three WU protocols. A lower value of FI may indicate a greater ability to maintain anaerobic performance that was obsvered in StreWU protocol. And, a higher FI value may show higher perssure on Taulo athletes during warm up resulting to insufficient recovery after warm up.

\section{PRACTICAL APPLICATIONS}

The results show that a suitable warm-up before a competition can increase the functionality by influencing different physiological parameters, but different strength and speed based-PAP warm up protonnls in thic ctudv did not create a cirnificant change in most of variables. Considerng these findings, Loading [MathJax]/jax/output/CommonHTML/jax.js

Page 12/18 
it is noted that the spicific sports such as Taolu form has not been affected by PAP WU protocols althought strengthed-based PAP protocols probably increase improvements in power-related performance in Taolu form. In additin, overly prolonged and/or intense warm-ups may generate more fatigue than potentiation, perhaps defeating the main purpose of this part of the training session. Finally, each athlete may perform the type of warm-up that enjoys the most, since similar effects will be produced and greater motivation may ensue. Future studies should expand on the inter-individual variability in response to different warm-up protocols, as well as analyze the individual motivations for performing each specific type of warm-up.

\section{Declarations}

"Authors: All research done by the authors";

"Financial support: no";

"Conflict of interest: none"

\section{ACKNOWLEDGMENTS}

The authors would like to acknowledge the elite Wushu athletes involved in this investigation.

\section{References}

1. Artioli, G.G., et al., Physiological, performance, and nutritional profile of the Brazilian Olympic Wushu (kung-fu) team. J Strength Cond Res, 2009. 23(1): p. 20-5.

2. Ribeiro, J.L., et al., Heart rate and blood lactate responses to changquan and daoshu forms of modern wushu. J Sports Sci Med, 2006. 5(Cssi): p. 1-4.

3. Bompa, T.O. and C.A. Buzzichelli, Periodization: Theory and Methodology of Training (6th Ed.). 2018, Champaign, IL: Human Kinetics.

4. Blagrove, R.C., et al., Efficacy of depth jumps to elicit a post-activation performance enhancement in junior endurance runners. Journal of Science and Medicine in Sport, 2019. 22(2): p. 239-244.

5. Till, K.A. and C. Cooke, The effects of postactivation potentiation on sprint and jump performance of male academy soccer players. J Strength Cond Res, 2009. 23(7): p. 1960-7.

6. Simpson, C.L., et al., Increase in post activation potentiation in females following a cycling warmup. Hum Mov Sci, 2018. 57: p. 171-177.

7. Alikhajeh, Y., et al., Differential Stretching Protocols During Warm up on Select Performance Measures for Elite Male Soccer Players. Procedia - Social and Behavioral Sciences, 2012. 46: p. 1639-1643.

8. Kay, A.D. and A.J. Blazevich, Effect of acute static stretch on maximal muscle performance: a systematic review. Med Sci Sports Exerc, 2012. 44(1): p. 154-64. 
9. Kallerud, $\mathrm{H}$. and N. Gleeson, Effects of stretching on performances involving stretch-shortening cycles. Sports Med, 2013. 43(8): p. 733-50.

10. Christensen, B., et al., The Effect of Static Stretching, Mini-Band Warm-Ups, Medicine-Ball Warm-Ups, and a Light Jogging Warm-Up on Common Athletic Ability Tests. International journal of exercise science, 2020. 13(4): p. 298-311.

11. Sale, D., Postactivation potentiation: role in performance. Br J Sports Med, 2004. 38(4): p. 386-7.

12. Fukutani, A., et al., Effect of conditioning contraction intensity on postactivation potentiation is muscle dependent. J Electromyogr Kinesiol, 2014. 24(2): p. 240-5.

13. Blazevich, A.J. and N. Babault, Post-activation potentiation versus post-activation performance enhancement in humans: historical perspective, underlying mechanisms, and current issues. Frontiers in Physiology, 2019. 10: p. 1359.

14. Prieske, O., et al., Time to differentiate postactivation "potentiation" from "performance enhancement" in the strength and conditioning community. Sports Medicine, 2020. 50: p. 15591565.

15. Zochowski, T., E. Johnson, and G.G. Sleivert, Effects of varying post-warm-up recovery time on 200-m time-trial swim performance. Int J Sports Physiol Perform, 2007. 2(2): p. 201-11.

16. José Afonso, C.B.a.R.J.F., Commentary: Do Thirty-Second Post-activation Potentiation Exercises Improve the 50-m Freestyle Sprint Performance in Adolescent Swimmers? Front. Physiol, 2019. 10(215): p. https://doi.org/10.3389/fphys.2019.00215.

17. Abbes, Z., et al., Do Thirty-Second Post-activation Potentiation Exercises Improve the 50-m Freestyle Sprint Performance in Adolescent Swimmers? Frontiers in physiology, 2018. 9: p. 1464-1464.

18. Mitchell, C.J. and D.G. Sale, Enhancement of jump performance after a 5-RM squat is associated with postactivation potentiation. Eur J Appl Physiol, 2011. 111(8): p. 1957-63.

19. Wilson, J.M., et al., Meta-analysis of postactivation potentiation and power: effects of conditioning activity, volume, gender, rest periods, and training status. J Strength Cond Res, 2013. 27(3): p. 854-9.

20. Reardon, D., et al., Do changes in muscle architecture affect post-activation potentiation? J Sports Sci Med, 2014. 13(3): p. 483-92.

21. Hancock, A.P., K.E. Sparks, and E.L. Kullman, Postactivation potentiation enhances swim performance in collegiate swimmers. J Strength Cond Res, 2015. 29(4): p. 912-7.

22. Jo, E., et al., Influence of recovery duration after a potentiating stimulus on muscular power in recreationally trained individuals. J Strength Cond Res, 2010. 24(2): p. 343-7.

23. Miarka, B., F.B. Del Vecchio, and E. Franchini, Acute effects and postactivation potentiation in the Special Judo Fitness Test. J Strength Cond Res, 2011. 25(2): p. 427-31.

24. Esformes, J.I., N. Cameron, and T.M. Bampouras, Postactivation potentiation following different modes of exercise. J Strength Cond Res, 2010. 24(7): p. 1911-6.

25. IWUF, 15th World Wushu Championships. 2019: http://www.iwuf.org/competition-results/. 
26. Gordon, S.A., et al., Comparison of methods to measure height in older adults. J Am Geriatr Soc, 2013. 61(12): p. 2244-6.

27. Hoshikawa, J.M., et al., Differences in muscularity of psoas major and thigh muscles in relation to sprint and vertical jump performances between elite young and professional soccer players, in Science and Football VI. The Proceedings of the Sixth World Congress on Science and Football, T. Reilly and F. Korkusuz, Editors. 2008, Routledge. p. 149-154.

28. Rahimi, R., The acute effects of heavy versus light-load squats on sprint performance. Facta Univ: Phys Educ Sport, 2007. 5(2): p. 163-169.

29. Smith, C.E., et al., The effects of a postactivation potentiation warm-up on subsequent sprint performance. Human Movement, 2014. 15(1): p. 36-44.

30. Baig, M.A., et al., Validating a point of care lactate meter in adult patients with sepsis presenting to the emergency department of a tertiary care hospital of a low-to middle-income country. World $\mathrm{J}$ Emerg Med, 2017. 8(3): p. 184-189.

31. Giles, D., N. Draper, and W. Neil, Validity of the Polar V800 heart rate monitor to measure RR intervals at rest. Eur J Appl Physiol, 2016. 116(3): p. 563-71.

32. Gore, C. and D.B. Pyne, How to interpret changes in an athletic performance test. Sportscience, 2004. 8.

33. Lachlan P James, M.C., G Gregory Haff, Vincent G Kelly, Emma M Beckman, The Countermovement Jump Mechanics of Mixed Martial Arts Competitors. J Strength Cond Res, 2020. 34(4): p. 982-987.

34. Goodwin, M.L., et al., Blood lactate measurements and analysis during exercise: a guide for clinicians. J Diabetes Sci Technol, 2007. 1(4): p. 558-69.

35. Faude, O., W. Kindermann, and T. Meyer, Lactate threshold concepts: how valid are they? Sports Med, 2009. 39(6): p. 469-90.

36. Queiroga, M.R., et al., Validity of the RAST for evaluating anaerobic power performance as compared to Wingate test in cycling athletes. Motriz: Revista de Educação Física, 2013. 19: p. 696-702.

37. Turfrey, R., Magnitude of Postactivation Potentiation response in elite rowers. 2014, Auckland University of Technology.

38. Afonso, J., C.F. Buzzachera, and R.J. Fernandes, Commentary: Do Thirty-Second Post-activation Potentiation Exercises Improve the 50-m Freestyle Sprint Performance in Adolescent Swimmers? Frontiers in physiology, 2019. 10: p. 215-215.

39. Baker, D. and R.U. Newton, Acute effect on power output of alternating an agonist and antagonist muscle exercise during complex training. The Journal of Strength \& Conditioning Research, 2005. 19(1): p. 202-205.

40. Brandenburg, J.P., The acute effects of prior dynamic resistance exercise using different loads on subsequent upper-body explosive performance in resistance-trained men. J Strength Cond Res, 2005. 19(2): p. 427-32. 
41. Linder, E.E., et al., Effects of preload 4 repetition maximum on 100-m sprint times in collegiate women. J Strength Cond Res, 2010. 24(5): p. 1184-90.

42. Young, W.B., A. Jenner, and K. Griffiths, Acute Enhancement of Power Performance From Heavy Load Squats. The Journal of Strength \& Conditioning Research, 1998. 12(2): p. 82-84.

43. Masamoto, N., et al., Acute effects of plyometric exercise on maximum squat performance in male athletes. J Strength Cond Res, 2003. 17(1): p. 68-71.

44. Chiu, L.Z., et al., Postactivation potentiation response in athletic and recreationally trained individuals. J Strength Cond Res, 2003. 17(4): p. 671-7.

45. Kobal, R., et al., Post-Activation Potentiation: Is there an Optimal Training Volume and Intensity to Induce Improvements in Vertical Jump Ability in Highly-Trained Subjects? J Hum Kinet, 2019. 66: p. 195-203.

46. Grosicki, G.J., M.E. Miller, and A.P. Marsh, Resistance exercise performance variability at submaximal intensities in older and younger adults. Clin Interv Aging, 2014. 9: p. 209-18.

\section{Figures}




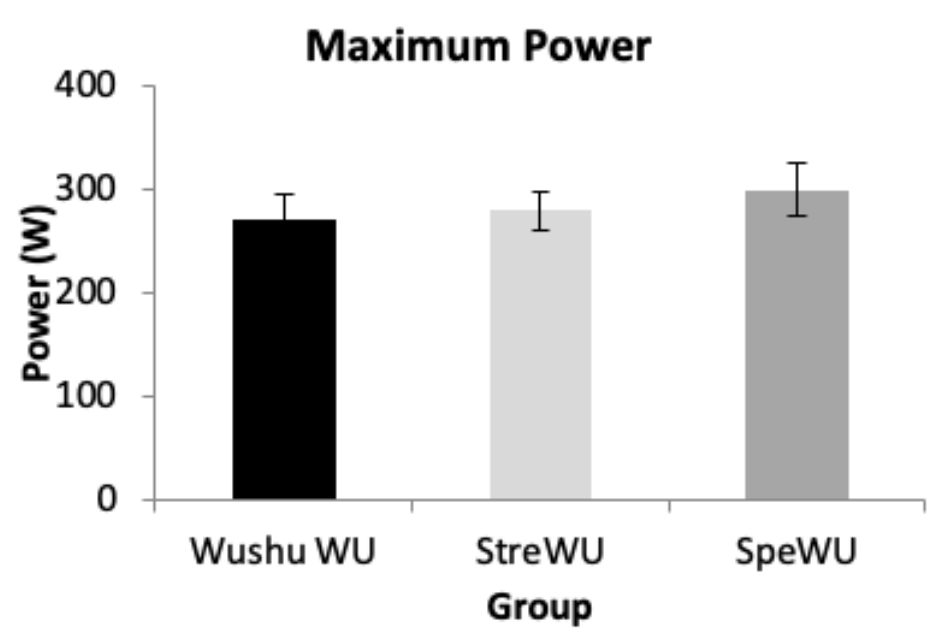

Minimum Power

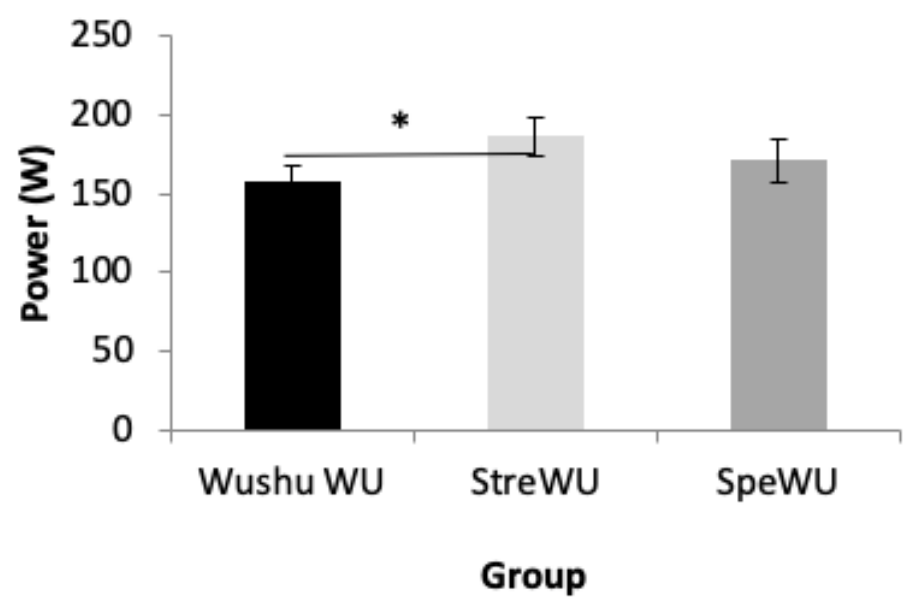

Mean Power

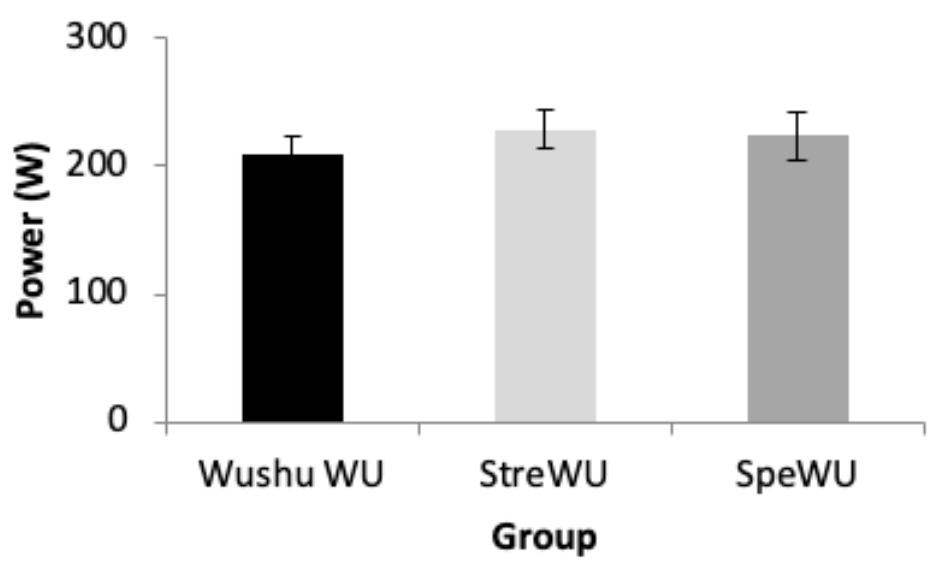

Fatigue Index

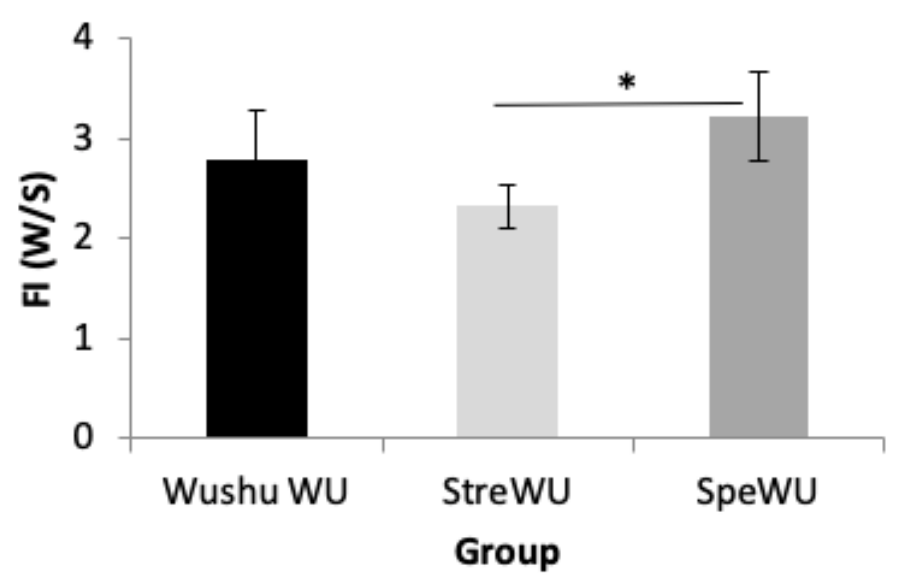

Figure 1

Maximum, mean, minimum power and fatigue index (FI) by warm-up protocol (Wushu WU: specific Wushu Warm-Up, StreWU: Strength-based Warm-Up, SpeWU: Speed-based Warm-Up). * significant difference at Minimum Power (between Wushu WU and StreWU) and FI (between StreWU and SpeWU) $(p=0.002$ and $p=0.024$, respectively). 


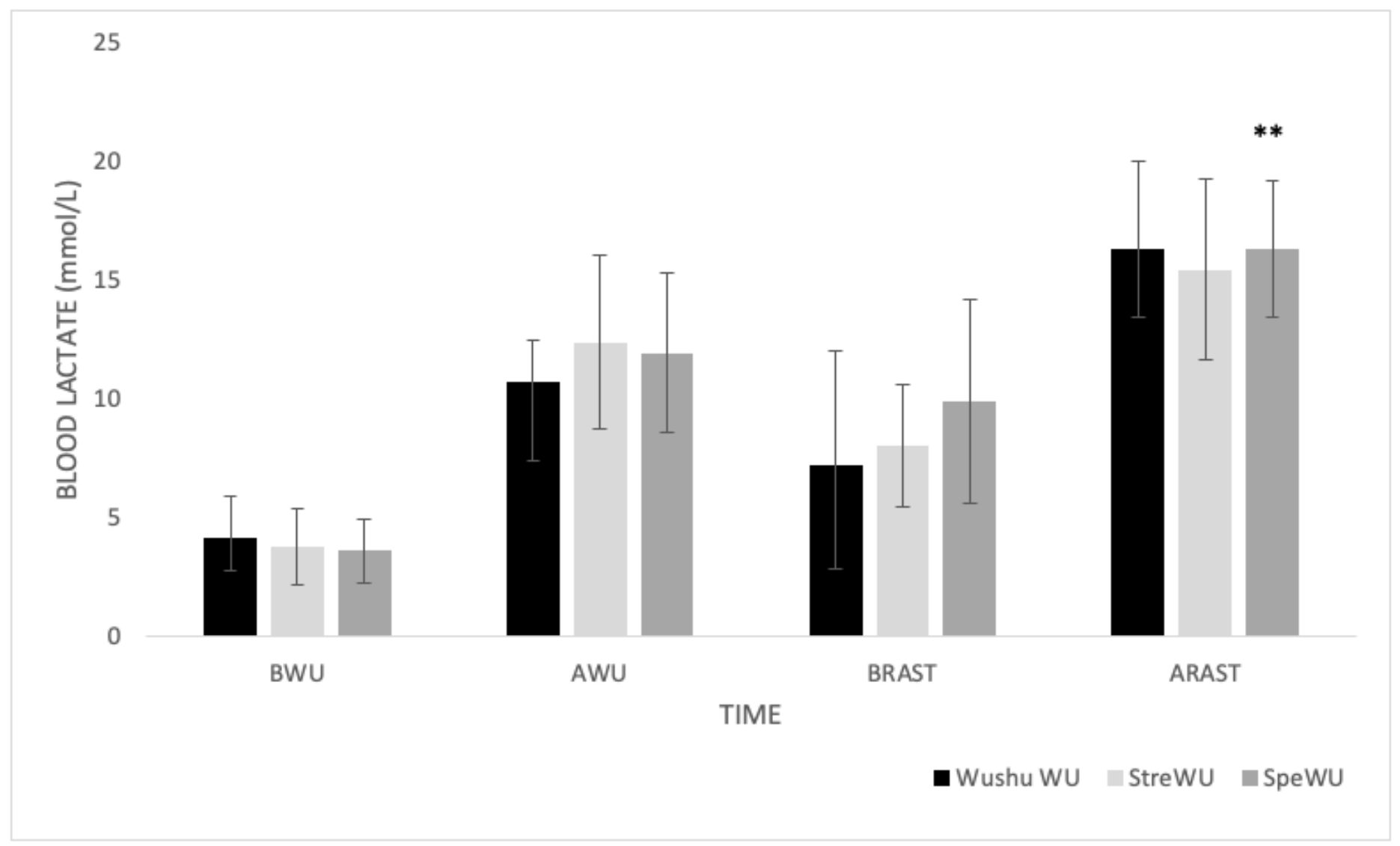

Figure 2

Mean value of lactate plasma levels for the three warm up protocols in 4 measurement times (Wushu WU: specific Wushu Warm-Up, StreWU: Strength-based Warm-Up, SpeWU: Speed-based Warm-Up, BWU: Before Warm Up, AWU: After Warm Up, BRAST: Before RAST, ARAST: After RAST). *significant differences in Lactate level in four measurement times (BWU, AWU, BRAST, and ARAST) in Wushu WU ( $p \leq 0.001)$. +significant differences in Lactate level in four measurement times (BWU, AWU, BRAST, and ARAST) in StreWU ( $p \leq 0.001) . * *$ significant differences in Lactate level in four measurement times (BWU, AWU, BRAST, and ARAST) in SpeWU ( $p \leq 0.001)$. 